\title{
PENERAPAN FUNGSI DAN PERAN AL- HISBAH DALAM PENGAWASAN DI BAITUL MAAL WA TAMWIL
}

\author{
Muhammad al ikhwan bintarto* \\ Magister Ilmu Hukum Universitas Muhammadiyah Yogyakarta \\ Luthfi Noor Mahmudi \\ Magister Hukum Ekonomi Syariah Universitas Darussalam Gontor \\ Ferdin Okta Wardana \\ Magister Ilmu Hukum Universitas Muhammadiyah Yogyakarta
}

\begin{abstract}
Supervision is an important thing in an activity, the purpose of supervision is so that an activity is in accordance with the plan and does not deviate from the specified path, Islam has carried out long supervision at the time of the Prophet which was carried out by the hisbah institution or market supervisory agency, the principle or concept of al-hisbah in carrying out supervision is amar ma'ruf nahi munkar, this research uses a qualitative method with a literature study with data collection techniques using literature studies where data sources are taken and collected from books, journals, previous research or from websites which are then read and processed into material. research, and the result of this study is that if Islamic financial institutions can implement the concept of al-hisbah institution it will minimize violations of sharia and remain within the scope of Islamic law.
\end{abstract}

Keywords: Al-hisbah, baitul maal wa tamwil

\section{Paper type: Research paper}

*Corresponding author: m.al.psc.20@umy.mail.ac.id

Received: September 07, 2021; Accepted: November 13, 2021; Available online: December, 06, 2021

Cite this document:

Bintarto, M. A.-I., Mahmudi, L. N., \& Wardana, F. O. (2021). Penerapan Fungsi dan Peran Al-Hisbah dalam Pengawasan di Baitul Maal Wa Tamwil. Jurnal Masharif Al-Syariah: Jurnal Ekonomi dan Perbankan Syariah, 6(3), 803-814. doi:http://dx.doi.org/10.30651/jms.v6i3.9800

Copyright (C) 2021, Jurnal Masharif Al-Syariah: Jurnal Ekonomi dan Perbankan Syariah

http://journal.um-surabaya.ac.id/index.php/Mas/index

This article is licensed under a Creative Commons Attribution-NonCommercial 4.0 International License. 


\begin{abstract}
Abstrak
Pengawasan merupakan suatu hal yang penting dalam suatu kegiatan, tujuan pengawasan adalah agar suatu kegiatan sesuai dengan rencana dan tidak menyimpang dari jalan yang telah ditentukan, Islam telah lama melakukan pengawasan pada zaman Rasulullah yang dilakukan oleh lembaga hisbah atau lembaga pengawas pasar, prinsip atau konsep alhisbah dalam melakukan pengawasan adalah amar ma'ruf nahi munkar, penelitian ini menggunakan metode kualitatif dengan studi kepustakaan dengan teknik pengumpulan data menggunakan studi kepustakaan dimana sumber data diambil dan dikumpulkan dari buku, jurnal, penelitian sebelumnya atau dari website yang kemudian dibaca dan diolah menjadi bahan. penelitian ini, dan hasil dari penelitian ini adalah jika lembaga keuangan syariah dapat menerapkan konsep lembaga al-hisbah maka akan meminimalkan pelanggaran syariah dan tetap dalam lingkup hukum Islam.
\end{abstract}

Kata kunci: Al-hisbah, baitul maal wa tamwil

\title{
PENDAHULUAN
}

Baitul maal sudah dikenal jauh pada tahun ke-2 hijriah di Madinah, dan berdirinya baitul maal didasarkan dikarenakan para sahabat berselisih tentang pembagian harta rampasan perang Badar dan kemudian turunlah surat al-anfal ayat 42 sehingga Rasulullah mendirikan baitul maal untuk mengatur harta benda kaum Muslimin dan Rasulpun menyerahkan urusan keuangan negara kepada lembaga keuangan ini dan kemudian baitul maal dikembangkan lebih jauh oleh kepemimpinan setelah Rasulullah.(Ifham, 2010)

Adapun BMT di Indonesia sendiri sampai dengan tahun 1993, mempunyai kegiatan operasional yang masih beragam baik dari sisi produk dan akad maupun sisi sistem operasionalnya. Dan Situasi perekonomian nasional yang mengalami krisis pada tahun 1991 melatarbelakangi munculnya kebijakan pemerintah yang dikenal dengan 
istilah "Tight Money Policy". Kebijakan ini disusul dengan kebijakan perbankan yang mempermudah pendirian bank.

Kebijakan ini mendorong umat untuk mendirikan bank syariah, khususnya skala mikro atau Bank Perkreditan Rakyat. Namun, kenyataannya masyarakat menghadapi banyak kendala untuk mendirikan BPR, terutama dari segi SDM dan modal dasar. Oleh karena itu, masyarakat lebih cenderung memilih mendirikan BMT. Beberapa BMT yang muncul pada masa itu antara lain: BMT BINAMA di Semarang, BMT TAMZIS di Wonosobo, BMT BUS di Lasem, dan BMT Beringharjo di Yogyakarta. Gerakan nasional BMT yang dimotori oleh PINBUK pada tahun 1995 tampaknya memiliki peran yang cukup penting dalam hal ini. Pada masa ini, BMT yang beroperasi di Indonesia merupakan lembaga keuangan dengan prinsip sistem perbankan syariah, yang kemudian diadopsi dan dilegalkan pemerintah melalui Departemen Koperasi dan UKMK dengan Keputusan Menteri UMKM No. 91/Kep/M.KUKM/IX/2004.(Widiyanto et al., 2016)

Dengan banyaknya BMT di Indonesia memunculkan pertanyaan dasar, apakah pengawasan di lembaga keuangan tersebut sudah sesuai dengan syariat Islam, beberapa kasus ditemukan oleh penulis tentang fraud atau penipuan diantaranya: BMT Perdana Surya Utama (PSU) Malang Yaitu dengan menjanjikan kepada nasabah berupa return saat berinvestasi dengan sistem bagi hasil $2 \%$ per bulan dan sudah ada 25 Milyar dana dikumpulkan dan sebesar 4 Miliar dikucurkan untuk keluarga pengurus BMT tersebut dan macet.(Anam, 2015) Kasus selanjutnya adalah Koperasi Syariah BMT Nusa Tanggul Welahan yang dilaporkan oleh nasabah atas dugaan penipuan dan penggelapan dana, salah satu nasabah menyebutkan bahwa penggelapan uang nilainya bervariasi mulai dari 5 juta rupiah hingga ratusan juta rupiah.(Rianto, 2018) Kemudian kasus BMT Fisabilillah yang melakukan penipuan dengan modus investasi dengan keuntungan sekitar 5-10\% per bulan dan nasabah tidak menerima hasil keuntungan setelah beberapa bulan selanjutnya.(KAWUL, 2018) 
Tujuan dari penelitian ini adalah untuk meningkatkan kinerja pengawasan yang dilakukan oleh Dewan Pengawas Syariah terhadap lembaga keuangan syariah dengan menerapkan konsep al-hisbah dalam islam seperti yang diterapkan oleh Rasulullah dan sahabatnya dalam mengawasi pasar.

\section{KAJIAN PUSTAKA}

\section{Baitul Maal Wa Tamwil}

Baitul Maal adalah berasal dari bahasa arab yang berarti rumah harta atau kas negara, yaitu sebagai lembaga yang diadakan dalam pemerintahan Islam untuk mengurus masalah keuangan negara. Atau, suatu lembaga keuangan negara yang bertugas menerima, menyimpan, dan mendistribusikan uang negara sesuai dengan syariat Islam.(Mardani, 2015) Dalam arti lain baitul maal mengarah pada usaha-usaha pengumpulan dan penyaluran dana yang non-profit, seperti; zakat, infaq, shodaqoh. Sedangkan baitut tamwil sebagai usaha pengumpulan dana dan penyaluran dana komersial. Usaha-usaha tersebut menjadi bagian yang tidak terpisahkan dari BMT sebagai lembaga pendukung kegiatan ekonomi masyarakat kecil dengan berlandaskan syariah.(Sudarsono, 2013) Baitul maal wa tamwil merupakan lembaga swadaya masyarakat yang didirikan dan dikembangkan di tengah masyarakat, terutama dalam awal pendiriannya biasanya dilakukan dengan sumber daya masyarakat itu sendiri.(Ahmad \& Harahap, 2020)

Baitul Maal Wa Tamwil muncul sebagai lembaga keuangan syariah mikro yang mengedepankan prinsip-prinsip ketauhidan, keadilan, kesetaraan dan kerjasama. Sistem tersebut bercirikan profit and Lost sharing, anti igharar, anti ikhtikar, ianti risywah, anti riba serta halal dan thoyyib.

Prinsip-prinsip pendirian Baitul Maal Wa Tamwil adalah prinsip keadilan, prinsip kesederajatan dan prinsip ketentraman, selain itu ada prinsip lain yaitu : 1. Keimanan dan ketaqwaan terhadap Allah Swt dengan mengimolementasikan prinsip-prinsip syariah dalam kegiatan 2 . Keterpaduan, yaitu nilai spriritual dan moral yang mengarahkan kepada 
etik bisnis yang dinamis, progresif, adil dan berakhlak mulia. 3 . Kekeluargaan. 4. Kebersamaan. 5. Kemandirian, 6. Profesionalisme, 7. Istiqomah yang berarti konsisten, konsekuen, kontinuitas dan berkelanjutan tanpa pernah putus asa.(Priyadi, 2018)

Dalam pendirian BMT di Indonesia dilandasi oleh tiga faktor,antara lain :

a. Faktor Filosofis

Secara Filosofis, gagasan pendirian BMT didasarkan pada kepentingan menjabarkan prinsip-prinsip ekonomi Islam (fiqh almuamalah) dalam praktik. Prinsip-prinsip ekonomi yang berdasarkan ketauhidan, keadilan, persamaan, kebebasan, tolong-menolong, dan toleransi menjadi kerangka filosofis bagi pendirian BMT di Indonesia. Selain itu, asas-asas muamalah seperi kekeluargaan, gotong-royong, mengambil manfaat dan menjauhi mudharat serta kepedulian terhadap golongan ekonomi lemah menjadi dasar utama bagi kepentingan mendirikan BMT di Indonesia.

b. Faktor Sosiologis.

Secara sosiologis, pendirian BMT di Indonesia adalah didasarkan pada adanya tuntutan dan dukungan dari umat Islam bagi adanya lembaga keuangan berdasarkan syariah. Seperti dikethui, ummat Islam merupakan mayoritas penduduk Indonesia, tetapi belum ada lembaga keuangan berdasarkan Syariah. Ide mendirikan BMT mencuat ke permukaan pada awal 1990-an.

c. Faktor Yuridis.

Secara Yuridis, Pendirian BMT di Indonesia diilhami oleh keluarnya kebijakan pemerintah berdasarkan UU No.7/1992 tentang perbankan dan PP No. 72 tentang Bank Perkreditan Rakyat berdasarkan bagi hasil. Ketika bank-bank syariah didirikan di beberapa wilayah, BMT-BMT pun tumbuh subur mengikuti kebijakan pemerintah tersebut.(Mardani, 2015) 


\section{Al-hisbah}

Pengertian Al- Hisbah dalam arti sempit dikenal dengan pengawas pasar atau lembaga pengawasan baik pemerintah atau swasta yang berwenang untuk mengawasi atas suatu hal. Dan arti Al- Hosbah secara luas adalah lembaga yang didirikan untuk menjamin kebaikan ketika kebaikan menurun dan mencegah kejahatan ketika tingkat kejahatan meningkat, khususnya dalam bidang perekonomian dan bisnis.(AlMawardi, 1960)

Beberapa ulama berpendapat tentang konsep Al-hisbah daiantaranya Al-Mawardi, Al-Saqati, Al-Ghazali dan Ibn Taimiyah, Alhisbah menurut AL-Mawardi adalah identik dengan konsep amar ma'ruf nahi munkar, Al- Mawardi mengelompokkan amar ma'ruf menjadi tiga kategori yakni: pertama, yang berhubungan dengan hak-hak Allah, kedua berhubungan dengan hak-hak manusia dan Ketiga, campuran antara hak Allah dan hak manusia.(Halim, 2011)Menurut Al-Saqati bahwa Al-hisbah perlu ditegakkan dalam kegiatan perekonomian misal perdagangan dll, dan dalam kegiatan muamalah apa saja yang perlu diawasi, al-Saqati berpegang teguh kepada hadist-hadist Nabi tentang bisnis yang dilarang.(Halim, 2011) Menurut Ibn Taimiyah lembaga hisbah dapat dibentuk sesuai kebutuhan, perubahan waktu dan budaya masyarakat karena ini adalah persoalan ijtihadi dan tidak dijelaskan secara eksplisit dalam syariat dan muhtasib atau pengawas yang ditunjuk harus figur yang amanah, bijaksana, adil dan taat kepad Allah dan Rasul.(Halim, 2011)

Sarjana konteporer yang merumuskan pengertian al-Hisbah diantaranya adalah Muhammad Mubarak dari Universitas Damaskus: "Hisbah adalah pengawasan administrasi yang dilaksanakan oleh pemerintah dengan menugaskan pejabat khusus untuk mengawasi masalah akhlaq, agama, ekonomi, tepatnya dalam lapangan sosial secara umum dalam rangka mewujudkan keadilan dan keutamaan yang sesuai dengan prinsip-prinsip yang terdapat dalam syariat Islam dan tradisi yang diakui oleh segala tempat dan zaman." 
Dari beberapa pendapat ulama diatas penuils menarik kesimpulan tentang kosep al hisbah yakni amar ma'ruf nahi munkar dan lembaga alHisbah dibentuk sebagai lembaga pengawasan untuk melindungi hak-hak seseorang dan mencegah dari keburukan yang mungkin dapat merugikakn orang lain dalam kegiatan muamalah.

Pengawasan dibagi menjadi dua yaitu pengawasan yang berwujud dan pengawasan yang tidak berwujud, pelaku pengawasan antara lain:

1. Tuhan sebagai penguasa alam semesta, dan dimanefestasikan dalam agama

2. Manusia pribadi baik atasan, bawahan atau diri sendiri

3. Sistem intern yang dibentuk dalam suatu lembaga

4. Lingkungan masyarakat baik sosial, budaya, adat stau kebiasaan

5. Gabungan anta masing-masing unsur diatas.

Orang yang melakukan pengawasan dalam konsep Al-Hisbah disebut muhtasib, muhtasib berasal dari kata bahasa arab hasabayahsubu hisaaban yang artinya menghitung. Arti dalam bahasa Indonesia adalah orang yang mengontrol atau mengawasi, melihat, menjaga baikbaik dan memperhatikan (atas sesuatu), dalam hal ini yakni orang yang mengawasi tentang lembaga keuangan.(Romli, 2015)

Fungsi dan peran industri lembaga Al-Hisbah dalam mengembangkan bidang perekonomian yaitu, fungsi lembaga Al-Hisbah adalah Al-amr bi al-ma,ruf wa nahi' an munkar dan juga bisa menjadi pendamai antar seseorang yang berselisih dalam lingkup yang diawasi oleh lembaga Al-Hisbah, tugas lainnya adalah mengawasi pasar dari segala bentuk kecurangan, penipuan dan hal lain yang dpat merugikan orang lain. Dan peran Al-Hisbah yaitu: 1. Melakukan pengawasan umum yang berkaitan degan kebijakan karena Al-hisbah bergerak dalam hal keagamaan dan hukum, 2. Dalam hal perindustrian Al-hisbah mengawasi tentang hal administratif dan pemeliharaan kualitas dan standar suatu produk, agar terhindar dari penipuan dan kecurangan dan menjaga harga agar tetap stabil.(Sukamto, 2016)

Dasar hukum pelaksanaan pengawasan yakni diantaranya 


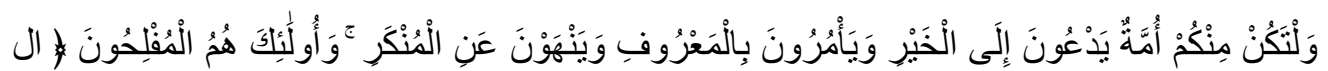

عمران : ع (1)

"Dan hendaklah ada di antara kamu segolongan umat yang menyeru kepada kebajikan, menyuruh kepada yang ma'ruf dan mencegah dari yang munkar, merekalah orang-orang yang beruntung". (Qs. Ali Imron :104)

Dan dalam hadist disebutkan

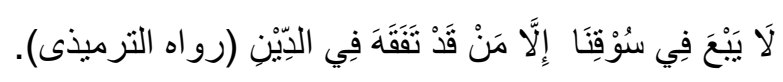

"Tidak boleh berjual-beli di pasar kami, kecuali orang yang benarbenar telah mengerti figh dalam agama Islam" (HR. at-Tirmidzi).

\section{METODE PENELITIAN}

Metode penelitian yang digunakan oleh penulis adalah penelitian kualitatif dan yang bersifat studi pustaka, dalam penelitian ini akan dilihat bagaimana implementasi konsep dan fungsi lembaga hisbah di zaman Rasulullah yang digunakan di lembaga keuangan mikro syariah, adapun teknik pengumpulan data dalam penelitian ini menggunakan studi literatur dimana sumber data diambil dan dikumpulkan dari buku, jurnal,penelitian terdahulu atau dari website yang kemudian dibaca dan diolah menjadi bahan penelitian, diharapkan dari penulisan ini konsep lembaga al-hisbah dapat menjadi sebuah contoh dan referensi untuk pengawasan di lembaga keuangan mikro syariah

\section{HASIL DAN PEMBAHASAN}

Penerapan Konsep, funsi dan peran Al-Hisbah di Baitul Maal Wa Tamwil

Pengawasan dalam islam dilaksanakan untuk meluruskan yang tidak lurus, mengoreksi sesuatu yang salah dan membenarkan sesuatu yang hak, dan pengawasan dalam Islam dibagi menjadi dua yaitu: Pertama, Pengawasan yang berasal dari dalam diri sendiri yang bersumber dari tauhid dan keimanan kepada Allah Swt, Kedua, sistem pengawasan dari luar diri sendiri atau dari orang lain. 
Penerapan Al-hisbah dalam lembaga keuangan syariah dapat disimpulkan dengan pembentukan Dewan Pengawas Syariah (DPS). Dewan Pengawas Syariah adalah lembaga independen yang mempunyai peran pengawasan terhadap sistem syariah di lembaga keuangan syariah.

Dalam Kamus Besar Bahasa Indonesia, dewan berarti Suatu badan majelis yang dibentuk dari beberapa orang anggota yang berugas untuk menasehati hingga memutuskan suatu hal, Pengawas berarti orang yang mengawasi dan Syariah adalah hukum Islam yang mengatur tentang tentang peraturan hidup manusia, baik hubungan antar manusia (hablu minannaas) atau hubungan manusia dengan Allah Swt (hablu minallah) berdasarkan Al-Qur'an dan hadist.

Sebagai lembaga pengawas, Dewan Pengawas Syariah (DPS) di Baitul maal wa tamwil mempunyai tugas dalam menyusun kebijakan unum BMT, melakukan pengawasan kegiatan dan operasional, menyetujui pembiayaan dalam jumlah tertentu dan memberikan rekomendasi produkproduk yang ditinjau sebelumnya dari syariah. Dan dalam melakukan tugas dan fungsi tersebut, anggota Dewan Pengawas Syariah harus memililiki kualifikasi yang integral yakni ilmu fiqih muamalay dan ilmu ekonomi keuangan Islam modern, dan apabila pengangkatan bukan didasarkan dari keilmuan yang dimilikinya maka fungsi DPS tidak maksimal dan tidak efektif yang dapat menyenankan terjasinya penyimpangan dari praktek syariah.

Dewan Pengawas Syariah (DPS) dibentuk Majelis Ulama Indonesia berdasarkan SK No. Kep-754/MUI/I/1999 pada tanggal 10 Februari 1999 tentang pembentukan Dewan Pengawas Syariah yang berfungsi untuk menymbuhkembangkan nilai-nilai syariah dalam kegiatan perekonomian pada umumnya dan pada bidang keuangan pada khususnya agar tidak terjadi hal yang menyeleweng dan bertentangan terhadap Syariat Islam.

Sistem pengawasan Dewan Pengawas Syariah yakni memeriksa, menginvestigasi dan memantau yang dimaksudkan agar menjaga kemaslahatan dan menghindari kerusakan dan kebathilan, Dewan Pengawas Syariah mengawasi berbagai aspek yakni produk dan jasa, 
manajemen dan pelayanan dan pembinaan anggota dan melakukan pengawasan terhadap seluruh orgasnisasi dan usaha baitul maal wa tamwil sehingga benar-benar sesuai dengan prinsip syariah Islam dan dapat konsisten serta menjalankan visi dan misi berdasarkan prinsip keadilan dan menjalankan operasional BMT secara syariat Islam sehingga mewujudkan bisnis yang berlabel secara syariat Islam.

Dewan Penawas Syariah dalam menjalankan tugasnya memiliki kewenangan diantaranya: 1 . DPS melakukan pengawasan secara periodik pada lembaga keuangan syariah yang berada di bawah pengawasannya, 2. DPS berkewajiban mengajukan usul-usul pengembangan lembaga keuangan syariah kepada pimpinan lembaga yang bersangkutan dan kepada DSN, 3. DPS melaporkan perkembangan produk dan operasional lembaga keuangan syariah yang diawasinya kepada DSN sekurangkurangnya dua kali dalam satu tahun anggaran, 4. DPS merumuskan permasalahan-permasalahan yang memerlukan pembahasan DSN.

\section{KESIMPULAN}

Fenomena lembaga hisbah sejatinya adalah kebutuhan masyarakat sehingga ia menjadi kewajiban negara untuk memenuhinya. Perkembangan terkini lebih memiliki spesifikasi seperti dalam bidang keuangan ada Otoritas Jasa Keuangan (OJK), Yayasan Lembaga Konsumen Indonesia (YLKI), Dewan Pengawas Syariah (DPS), dll.

Konsep al-Hisbah dalam pengawasan adalah amar ma'ruf nahi munkar yang bermakna luas apabila diaplikasikan dalam kegiatan muamalah, salah satunya adalah pembentukan Dewan Pengawas Syariah untuk lembaga keuangan syariah yang berfungsi untuk menjaga lembaga keuangan tersebut tetap dalam prinsip syariah Islam dan tidak menyeleweng. Penerapan fungsi dan peran Al-hisbah dalam pengawasan Dewan Pengawas Syariah di lembaga keuangan mikro syariah dangatlah penting demi menjalankan operasional dan kegiatan nya secara syariat Islam dan nantinya berdampak pada optimalisasi fungsi Lembaga keuangan syariah tersebut berdasarkan syariat Islam dan diharapkan hasil dari pengawasan antara lain: Seluruh operasional dan akad-akad sesuai 
dengan prinsip syariah, pengurus mempunyai aqidah dan akhlak yang baik dan patuh akan syariah Islam, BMT tidak memiliki daftar hitam atau masalah di dalamnya, terciptanya budaya Islami di kalangan BMT, berkembangnya BMT seiring dengan munculnya program dan akad yang Islami.

Penulis menyarankan agar perbankan syariah atau BPRS dapat mengoptimalkan pengawasan dalam operasional maupun akad sehingga tidak keluar dari prinsip syariah Islam.

\section{DAFTAR PUSTAKA}

Ahmad, S., \& Harahap, R. (2020). Peran Baitul Mal Wa Tamwil (Bmt) Dalam Pengembangan Ekonomi Umat. Human Falah, 7(1), 1929.

Al-Mawardi. (1960). al ahkam al-Sultaniyyah. Mustafa al-Babi al Halab.

Anam, C. (2015). Satgas Investasi telusuri Kasus BMT PSU Malang. http://finansial.bisnis.com/

Halim, M. (2011). Eksistensi Wilayatul Hisbah dalam Sistem Pemerintahan Islam. Jurnal IImiah Islam Futura, 10(2), 65-81.

Ifham, A. S. (2010). Buku Pintar Ekonomi Syariah (pertama). Gramedia Pustaka Utama.

KAWUL, I. (2018). Nasabah BMT di Wonogiri Resah, Tabungan Miliaran Tak

Bisa

Cair. http://www.kebumenekspres.com/2017/02/nasabah-bmt-diwonogiri-resah-tabungan.html

Mardani. (2015). Aspek hukun Lembaga Keuangan Syariah di Indonesia. Prenandamedia Group.

Priyadi, U. (2018). Teori dan Aplikasi Lembaga Keuangan Mikro Syariah (1st ed.). UII Press.

Rianto, B. (2018). Tipu Nasabah Miliaran Rupiah, Koperasi BMT Nusa Dilaporkan ke Polisi. https://www.antvklik.com/headline/ditipumiliaran-puluhan-nasabah-lapor

Romli. (2015). Al-Hisbah Al-Islamiyah Sistem Pengawasan Pasar dalam islam (1st ed.). DeePublish.

Sudarsono, H. (2013). Bank dan Lembaga Keuangan Syariah Deskripsi dan Ilustrasi (4th ed.). Ekonisia Kampus UII fakultas ekonomi.

Sukamto. (2016). Kontektualisasi Institusi Hisbah dalam Perekonomian Indonesia Praspektif Maqashid Syariah. Malia, 7(1), 59-80.

Widiyanto, Ismail, A. G., \& Wibowo, K. A. (2016). BMT: Praktik dan Kasus 
(1st ed.). Raja Grafindo Persada. 